Research Article

\title{
Enhancement of Mechanical Properties of Polyamide Hexaglycol by Dispersion of $\mathrm{TiO}_{2}$ Nanofiller
}

\author{
Sabah Mohammed Mlkat Al-Mutoki ${ }^{1}$, Baydaa Abdul-Hassan Khalaf Al-Ghzawi ${ }^{2}$ \\ Emad Abbas Jaffar Al-Mulla ${ }^{3}$, Samer AbdulAmohsin ${ }^{4}$ \\ ${ }^{1}$ Electrical Department, Al Furat Al Awsat University, Technical Institute of Samawa, Samawa, Iraq. \\ ${ }^{2}$ Mechanical Department, Al Furat Al Awsat University, Technical Institute of Samawa, Samawa, Iraq. \\ ${ }^{3}$ Department of Chemistry, Faculty of Science, University of Kufa, P.O. Box 21, An-Najaf 54001, Iraq. \\ ${ }^{4}$ Physical Department, Faculty of Science, Thi Qar University, Thi Qar, Iraq. \\ —Corresponding author: E-mail: asabah_sh2003@yahoo.com; imad.almulla@uokufa.edu.iq
}

Received: Feb. 3, 2016; Accepted: Feb. 18, 2016; Published: Apr. 28, 2016.

Citation: Sabah Mohammed Mlkat Al-Mutoki, Baydaa Abdul-Hassan Khalaf Al-Ghzawi, Emad Abbas Jaffar Al-Mulla and Samer AbdulAmohsin,

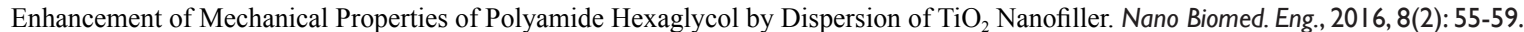

DOI: 10.5101/nbe.v8i2.p55-59.

\begin{abstract}
The effects of $1,2,3,4$, and $5 \mathrm{wt} \%$ of $\mathrm{TiO} 2$ disperse nanofiller on mechanical properties of polyamide hexaglycol (PAHG) were investigated. Specimen was prepared by the hot vibration dispersion technique to make a PMNC. Hardness, tensile strength, ultimate tensile strength, young modulus, and impact at room temperature were tested. It has been found that enhancement in these properties starts at extra low weight percent $(1 \mathrm{wt} \%) \mathrm{nTiO}_{2}$. The maximum effect of nano $\mathrm{TiO}_{2}$ addition was on tensile strength, and the lowest was on young modulus.
\end{abstract}

Keywords: Nanofiller; PMNCs; Hot vibration dispersion

\section{Introduction}

The reinforcement of polymers using fillers, whether inorganic or organic, is common in the production of modern plastics. Polymeric nanocomposites (PNCs) represent a radical alternative to the conventional filled polymers or polymer blends. In contrast to conventional systems, where the reinforcement is of the order of microns, PNCs are exemplified by discrete constituents of the order of a few nanometers $(<100 \mathrm{~nm})$ in at least one dimension [1-4]. The small size of the fillers leads to an exceptionally large interfacial area in the composites. The interface controls the degree of interaction between the filler and the polymer and thus controls the properties. As in conventional composites, the interfacial region is the region beginning at the point in the fibre at which the properties differ from those of the bulk filler and ending at the point in the matrix at which the properties become equal to those of the bulk matrix [5-8]. Nanometer-sized fillers have been made from different organic and inorganic particles, and they impart improved properties to composite materials [9]. Different fillers have been used to prepare polymer/ inorganic particle nanocomposites, including metals ( $\mathrm{Al}, \mathrm{Fe}$, etc.), metal oxides $\left(\mathrm{ZnO}, \mathrm{Al}_{2} \mathrm{O}_{3}, \mathrm{TiO}_{2}\right.$, etc.), nonmetal oxide $\left(\mathrm{SiO}_{2}\right)$, and others $(\mathrm{SiC})$ [9-14]. The selection of nanoparticle filler depends on the desired thermal, mechanical, and electrical properties of the nanocomposites [15-29]. The aim of this research 
was to study the effect of the weight percent of $\mathrm{TiO}_{2}$ anatase nanofiller particles on the hardness, tensile strength, and creep at room termperature of nano $\mathrm{TiO}_{2} /$ PAHG polymer matrix composite.

\section{Experimental Work}

\section{Materials}

Polyamide hexaglycol (PAHG) containing resin and hardener was supplied from SICOMIN, USA, and 99.9\% $\mathrm{TiO}_{2}$ purchased from HORIBA, Germany with 10-30 nm particle size range were used as a matrix and a nanofiller. Mechanical properties of both polymer matrix and ceramic nanofiller are listed in Table 1.

Table 1 Mechanical Properties of PAHG, and $\mathrm{nTiO}_{2}$

\begin{tabular}{ccc}
\hline Property & PAHG & $\mathrm{nTiO}_{2}$ \\
\hline BHN (MPa) & 26 & 130 \\
T.S. (MPa) & 15 & 344 \\
U.T.S (MPa) & 107 & 800 \\
E (GPa) & 42 & 122 \\
Impact & 50 & 415 \\
\hline
\end{tabular}

\section{Specimen preparation}

Weighing: Table 2 illustrates the weights of $\mathrm{nTiO}_{2}$, PAHG resin, and PAHG hardener; weight percent of PAHG resin to hardener was 1:3.

Table 2 Weights (gm) of $\mathrm{nTiO}_{2}$, PAHG resin/hardener

\begin{tabular}{ccc}
\hline Specimen & $\mathrm{nTiO}_{2}$ & PAHG \\
\hline 1 & 1 & 66 resin +33 hardener \\
2 & 2 & 65.4 resin +32.6 hardener \\
3 & 3 & 64.7 resin +32.3 hadener \\
4 & 4 & 64 resin +32 hardener \\
5 & 5 & 63.7 resin +31.3 hardener \\
\hline
\end{tabular}

\section{Mixing and solidification}

After weighing powder of $\mathrm{nTiO}_{2}$ was mixed with PAHG resin using a magnetic stirrer with a very low speed $(30 \mathrm{rpm})$ for $15 \mathrm{~min}$ at $50^{\circ} \mathrm{C}$, the hardener was dropped over the mixture with continuous stirring at the same speed for $20 \mathrm{~min}$ at room temperature. And then the mixture was poured in a special mold according to the different standard shapes of tests, left for $24 \mathrm{hrs}$ at room temperature for solidification.

\section{Testing}

Brinell testing device type (Wilson instrument,
Hardness tester, USA) with a tungsten carbide ball (10 $\mathrm{mm}$ in diameter) was applied according to ASTM D730-98. The device was connected to a digital system type (Sony 210) which gave direct results.

Tensile test was conducted according to ASTM E 623-92, using a set type (Instron 1195 Tensile Test) with the load of $5 \mathrm{KN}$ and the strain range of $0.5 \mathrm{~mm} /$ $\min$. The device was connected to a digital reading and graphing unit type PLC 1800.

Charpy impact test device type CDM, U.K results were calculated according to Equation (1).

$\mathrm{E}=\mathrm{mg}\left(\mathrm{h}_{1}-\mathrm{h}_{2}\right)$

where $\mathrm{m}$ was the mass of pendulum $(25 \mathrm{~kg})$, g was the acceleration (9.8), and $h_{1}, h_{2}$ were the heights of the pendulum before and after striking the specimen, respectively.

\section{Results}

Figure 1 illustrates SEM of PAHG/nTiO $(\mathrm{PMNC})$. We can see the good dispersion and high interaction between the polymer matrix and nano reinforcing particles. This may lead us to concluding that there is an enhancement in mechanical properties even at low $\mathrm{nTiO}_{2}$ filler, as we shall see.

Table 3 illustrates the tensile strength, ultimate tensile strength, and young modulus of PAHG/nTiO PMNC.

Table 3 Mechanical Properties of PAHG/nTiO ${ }_{2}$ PMNC

\begin{tabular}{lcccccc}
\hline & \multicolumn{5}{c}{$\mathrm{TiO}_{2} / \%$} \\
\cline { 2 - 6 } \multicolumn{1}{c}{ Mechanical Property } & 1 & 2 & 3 & 4 & 5 \\
\hline Tensile strength (MPa) & 180 & 380 & 593 & 820 & 1460 \\
Ultimate Tensile Strength (MPa) & 270 & 512 & 874 & 1050 & 2600 \\
Young Modulus (GPa) & 110 & 317 & 548 & 927 & 1138 \\
Brinell Hardness Number (MPa) & 83 & 171 & 326 & 781 & 1297 \\
Impact (J) & 275 & 498 & 863 & 1023 & 2468 \\
\hline
\end{tabular}

\section{Discussion}

The nanoscale reinforcing phase can be grouped into three categories: nano particles (0-D), nanotubes (1D), and nanoplates (2-D). In such case of nanoparticles as in our research, the particle size and distribution 


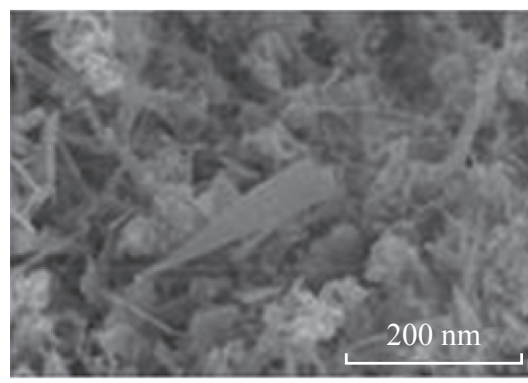

(a)

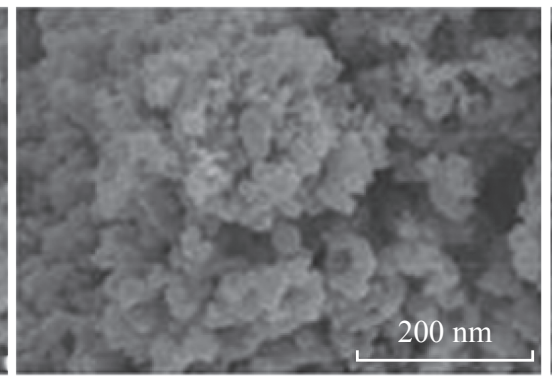

(b)

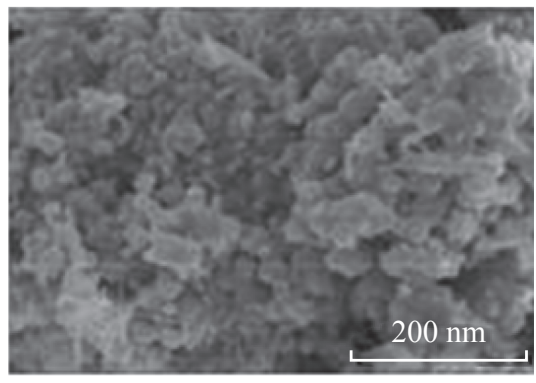

(c)

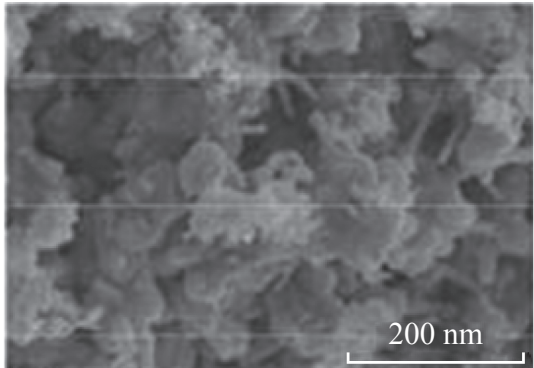

(d)

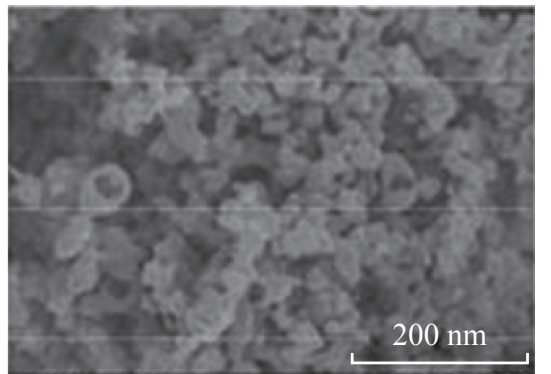

(e)

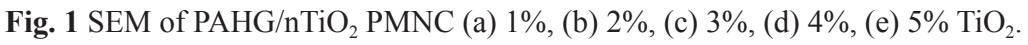

are of great importance. Depending on the types of nanoparticles added, the mechanical properties of PMNC can be altered. The changes in modulus and strength depend strongly on the degree of interaction between the nano reinforcing particles and the polymer matrix. Figure 1 illustrates SEM of PAHG/nTiO (PMNC). We can see the good dispersion and high interaction between the polymer matrix and nano reinforcing particles; this may lead us to concluding that there is an enhancement in mechanical properties even at low $\mathrm{nTiO}_{2}$ filler, as can we see from Table 3 which shows the mechanical properties of PAHG/ $\mathrm{nTiO}_{2}(\mathrm{PMNC})$. The tensile strength of polymer matrix nanocomposites (PMNCs) is the force required to pull the composite to the point where it breaks. Practically, the tensile strength of a PMNC is the maximum amount of tensle stress that can be subjected to before failure. That PAHG is a brittle (Table 1) material means that it does not have a yield point, and that the ultimate tensile strength (UTS) and breaking strength are the same. The advantages of using nanoparticles as the reinforcement is that their size is smaller than the critical crack length that typically initiates failure in the composite, and as a result, nano reinforcing particles provide improved strength.

When we compare the values of mechanical properties of PAHG polymer matrix, $\mathrm{nTiO}_{2}$ particles listed in Table 1, and those of PAHG/nTiO 2 PMNC produced from them, we may conclude the following points:

1. The effect of $\mathrm{nTiO}_{2}$ addition starts to show on different mechanical properties even at the extra low weight percent. For example, the addition of $1 \% \mathrm{Wt} \mathrm{nTiO}{ }_{2}$ increases the tensile strength from 15 MPa which may be a neglected value up to $180 \mathrm{MPa}$ directly, while the other properties as ultimate tensile strength, Brinell hardness number, impact, and young modulus values increase from 107, 26, 55 and 22 MPa respectively up to $270,83,275$ and $110 \mathrm{GPa}$ respectively. This increasing effect continues with the addition of weight percent till it reaches its maximum value at $5 \% \mathrm{nTiO}_{2} \mathrm{wt} \%$ for all properties (Table 3).

This large enhancement in mechanical properties makes the PAHG/nTiO ${ }_{2} \mathrm{PMNC}$ reach at some points to the excellent mechanical properties of metals and certain types of ceramic.

2. The increscence in mechanical properties of $\mathrm{PAHG} / \mathrm{nTiO}_{2} \mathrm{PMNC}$ is irregular in spite of the regular increase in $\mathrm{nTiO}_{2}$ weight percent. This can be explained by looking at Fig. 1 which shows the SEM images of $1,2,3,4,5) \mathrm{wt} \%$ of $\mathrm{nTiO}_{2}$. From this figure we may notice the differences between the dispersion patterns of specimens, and that the concentration areas of reinforcing $\mathrm{nTiO}_{2}$ through the PAHG polymer matrix lead to this irregularity in the increscence of mechanical properties of the produced PAHG/nTiO 2 PMNC. We must also consider that 
the physical interaction between PAHG matrix and $\mathrm{nTiO}_{2}$ reinforcement increases with the increasing of $\mathrm{nTiO}_{2}$ weight percent due to the increase in the contact surface area between both polymer matrix (PAHG) and $\mathrm{nTiO}_{2}$ reinforcement, leading to an increase in all the properties of polymer matrix nano composite, and hence enhances mechanical properties.

3. Despite the fact that the addition of $\mathrm{nTiO}_{2}$ particles leads to a huge enhancement in mechanical properties (in our research), but this enhancement is not equal all over the studied properties. In a simple frame, $\mathrm{nTiO}_{2}$ addition effects on some properties greater than the others. At the weight percent of $5 \% \mathrm{nTiO}_{2}$ as an example, we may arrange the properties according to their changes with the $\mathrm{nTiO}_{2}$ addition as follows (Tables 1 and 3):

i. Tensile strength increased from $15 \mathrm{MPa}$ for PAHG matrix up to 1460 or $1.460 \mathrm{GPa}$, while the ultimate tensile strength increased from 22 up to 2600 or $2.6 \mathrm{GPa}$.

ii. The effect on Brinell hardness number came in the second stage, increasing from 26 to 1297 or $1.297 \mathrm{GPa}$.

iii. Impact value was only $55 \mathrm{~J}$ for PAHG and increased to $2468 \mathrm{~J}$ for $\mathrm{PAHG} / \mathrm{nTiO}_{2} \mathrm{PMNC}_{\text {. }}$

iv. The lowest effect for $\mathrm{nTiO}_{2}$ addition was on young modulus which increased from $40 \mathrm{MPa}$ for PAHG up to 1138 or $1.138 \mathrm{GPa}$ for PAHG/nTiO 2 PMNC.

The enhancement in mechanical properties of $\mathrm{PAHG} / \mathrm{nTiO}_{2}$ PMNC makes it useful in applications where low weight and high mechanical properties are required, such as protective body armor substrates.

\section{Conclusions}

The addition of $1-5 \% \mathrm{nTiO}_{2}$ to PAHG increased the hardness, tensile strength, ultimate tensile strength, young modulus, and impact strength. A $5 \% \mathrm{nTiO}_{2}$ specimen gave the highest change, and the most effect was on tensile strength.

\section{Competing Interests}

The authors declare that they have no competing interests.

\section{Acknowledgments}

All technical staff in both Electrical Department and Mechanical Department, Al Furat Al Awsat University, Technical Institute of Samawa, Samawa, Iraq are greatly acknowledged for their assistance.

\section{References}

[1] W.M.Z. Yunus, N.A.B. Ibrahim and M.Z.A. Rahman, Epoxidized palm oil plasticized polylactic acid/fatty nitrogen compound modified clay nanocomposites: preparation and characterization. Polym. Polym. Comp, 2010, 18: 451-459.

[2] F.A. Shemmari, A.A. Rabah, A comparative study of different surfactants for natural rubber clay nanocomposite preparation. Rendiconti Lincei Scienze Fisiche E Naturali, 2014, 25: 409-413.

[3] T.A. Mohammed, N.K. Abd Khadir, New polyurethane nanocomposites based on soya oil. J. Oleo Sci., 2014, 63:193-200.

[4] H. Yang, Z. Ge, C. Zou, et al., Detection of nanobubbles at the interface $\mathrm{TiO}_{2}$ coated mica in water. Nano Biomed. Eng., 2009, 1(1): 75-79.

[5] H. Li, Y. Zhang and W. Huang, Novel selective sensors based on $\mathrm{TiO}_{2}$ nanotubes supported $\mathrm{MS}\left(\mathrm{TiO}_{2} @ \mathrm{MS}\right.$, $\mathrm{M}=\mathrm{Cd}, \mathrm{Zn}$ ) for their gas sensing properties. Nano Biomed. Eng., 2010, 2(2): 143-148.

[6] E.A.J. Al-Mulla, A new biopolymer-based polycaprolactone/starch modified clay nanocomposite. Cellulose Chem. Tech., 2014, 48(5-6): 515-520.

[7] D.V. Szabó, S. Schlabach and R. Ochs, Analytical TEM investigations of size effects in $\mathrm{SnO}_{2}$ nanoparticles produced by microwave plasma synthesis. Microsc. Microanal, 2007, 13: 430-431.

[8] H.H. Balla, S. Abdullah, Effect of reynolds number on heat transfer and flow for multi-oxide nanofluids using numerical simulation. Res. Chem. Intermed., 2013, 39(5): 2197-2210.

[9] S. Li, W.T. Zheng and Q. Jiang, Size and pressure effects on solid transition temperatures of $\mathrm{ZrO}_{2}$. Scr. Mater. 2008, 24: 2091-2094.

[10] H. Zhang, J.F. Banfield, Thermodynamic analysis of phase stability of nanocrystalline titania. J. Mater. Chem, 1998, 8: 2073-2076.

[11] S. Schlabach, D.V. Szabó and D. Vollath, Structure and grain growth of $\mathrm{TiO}_{2}$ nanoparticles investigated by electron and X-ray diffractions and Ta-181 perturbed angular correlations. J. Appl. Phys, 2006, 100, 024305: 1-024305: 9.

[12] D.V. Szabó, S. Schlabach and D. Vollath, Zirconia and titania nanoparticles studied by electric hyperfine interactions, XRD and TEM. J. Alloy. Compd, 2012, 434: 590-593

[13] M. Zhang, G. Lin, C. Dong, et al., Amorphous $\mathrm{TiO}_{2}$ films with high refractive index deposited by pulsed bias arc ion plating. Surf. Coat. Tech, 2007, 201: 7252-7258.

[14] C. Jiang, M. Wei and Z. Qi, Particle size dependence of the lithium storage capability and high rate performance of nanocrystalline anatase $\mathrm{TiO}_{2}$ electrode. J. PowerSources, 2009, 166: 239-243.

[15] C.H. Jiang, I. Honma and T. Kudo, Nanocrystalline rutile $\mathrm{TiO}_{2}$ electrode for highcapacity and high-rate lithium storage. Electrochem. Solid-State Lett., 2007, 10: A127-A129.

[16] D. Deng, M.G. Kim, J.Y. Lee, et al., Green energy storage materials: nanostructured $\mathrm{TiO}_{2}$ and $\mathrm{Sn}$-based anodes for lithium-ion batteries. Energy Environ. Sci., 2009, 2: 818837. 
[17] S. Chattopadhyay, P. Ayyub and V.R. Palkar, Finite-size effects in antiferroelectric $\mathrm{PbZrO}_{3}$ nanoparticles. J. PhysCondens. Mat., 1997, 9: 8135-8145.

[18] T. Yan, Z.G. Shen, W.W. Zhang, et al., Size dependence on the ferroelectric transition of nanosized $\mathrm{BaTiO}_{3}$ particles. Mater. Chem. Phys., 2006, 98: 450-455.

[19] S. Wada, T. Hoshina, H. Yasuno, et al., Size effect of dielectric properties for barium titanate particles and its model. Key Eng. Mat., 2013, 301: 27-30.

[20] N.A. Ibrahim, M.Z.A. Rahman, Difatty acyl urea from corn oil: synthesis and characterization. J. Oleo Sci., 2010, 59(3): 157-160.

[21] L.S. Schadler, L.C. Brinson and W.G. Sawyer, Polymer nanocomposites: a small part of the story. J. Miner. Met. Mater. Soc., 2007, 59: 53-60.

[22] I.A. Mohammed, N.K. Kadar and M. Ibrahim, Structureproperty studies of thermoplastic and thermosetting polyurethanes using palm and soya oils-based polyols. $J$. Oleo Sci., 2013, 62(12): 1059-1072.

[23] N.A.B. Ibrahim, K. Shameli, M.B. Ahmad, et al., Effect of epoxidized palm oil on the mechanical and morphological properties of a PLA-PCL blend. Res. Chem. Intermed., 40(2): 689-698.

[24] Z. Dang, Y. Xia and J. Bai, Preparation and dielectric properties of surface modified $\mathrm{TiO}_{2} /$ silicon rubber nanocomposite. Materials Letters, 2011, 65(23): 34303432 .
[25] M.M. Radhi, E.A.J. Al-Mulla, Electrochemical oxidation effect of ascorbic acid on mercury ions in blood sample using cyclic voltammetry. Int. J. Ind. Chem., 2015, 6(4): 311-316.

[26] E. Tuncer, G. Polizos, I. Sauers, et al., Epoxy nanodielectrics fabricated with in-situ and ex-situ techniques. J. Experim. Nanosci., 2011, 7: 274-281.

[27] D.Q. Tan, Y. Cao and P. Irwin, Nanostructured dielectric materials. International Conference on Solid Dielectrics, Winchester, 8-13 July 2007, pp. 411-414.

[28] S.M.M. Al-Mutoki, B.A.K. Al-Ghzawi, A.A. Abdullah, et al., Synthesis and characterization of new epoxy/titanium dioxide nanocomposite. Nano Biomed. Eng., 2015, 7(4): 135-138.

[29] P. Kim, S.C. Jones, P.J. Hotchkiss, et al., Phosphonic acid-modified barium titanate polymer nanocomposites with high permittivity and dielectric strength. Advanced Materials, 2007, 19: 1001-1005.

Copyright $@ 2016$ Sabah Mohammed Mlkat Al-Mutoki, Baydaa Abdul-Hassan Khalaf Al-Ghzawi, Emad Abbas Jaffar Al-Mulla and Samer AbdulAmohsin. This is an open-access article distributed under the terms of the Creative Commons Attribution License, which permits unrestricted use, distribution, and reproduction in any medium, provided the original author and source are credited. 